\title{
ASPEK E-FILING DENGAN KETAATAN WAJIB PAJAK MELALUI MODERASI KECAKAPAN INTERNET DAN BIAYA KETAATAN
}

\author{
Asbi Amin ${ }^{1}$, Andi Marlinah ${ }^{* 2}$, Sukmawati ${ }^{3}$ \\ 1,3 STIEM Bongaya, Makassar \\ ${ }^{2 *}$ Jurusan Akuntansi, STIE Nobel Indonesia Makassar \\ e-mail: *11 asbi.amin@ @stiem-bongaya.ac.id, ${ }^{2}$ marlinah@ stienobel-indonesia.ac.id, \\ ssukmawati@gmail.com
}

\begin{abstract}
Abstrak
Tujuan penelitian ini adalah untuk menganalisis $e$-filing berpengaruh pada ketaatan wajib pajak, untuk menganalisis $e$-filing berpengaruh pada ketaatan wajib melalui moderasi kecakapan internet dan untuk menganalisis $e$-filing berpengaruh pada ketaatan wajib pajak dengan tidak dimoderasi oleh biaya ketaatan. Data dikumpulkan melalui kuesioner yang didistribusikan kepada sampel dengan teknik accidental sampling kepada 100 wajib pajak orang pribadi di KPP Makassar Barat. Analisis data dengan pendekatan Moderated Regression Analysis (MRA). Hasil penelitian menemukan bahwa penerapan $e$ filing positif dan signifikan memengaruhi ketaatan, kecakapan internet sebagai pemoderasi hubungan $e$ filing dengan ketaatan wajib pajak sedangkan biaya ketaatan bukan pemoderasi hubungan $e$-filing dengan ketaatan wajib pajak.
\end{abstract}

Kata Kunci : $e$-filing; kecakapan internet; biaya ketaatan; ketaatan wajib pajak.

\section{Abstract}

The purpose of this research was to analyze e-filing effect on taxpayer compliance, to analyze e-filing effect on mandatory compliance through moderation of internet skills and to analyze e-filing effect on taxpayer compliance without being moderated by compliance costs. Data were collected questionnaires which were distributing to the sample with accidental sampling technique to 100 individual taxpayers at KPP Makassar Barat. Data analysis using the Moderated Regression Analysis (MRA) approach. The results of the study found that the application of e-filing positively and significantly affects taxpayer compliance, internet proficiency as moderating the relationship between e-filing and taxpayer compliance, while compliance costs do not moderate the relationship between e-filing and taxpayer compliance.

Keywords: application of e-filing; internet proficiency; compliance costs; taxpayer compliance.

\section{PENDAHULUAN}

Transformasi pelaporan pajak terus dilakukan oleh pemerintah untuk meningkatkan nilai kepatuhan pelaporan perpajakan masyarakat agar dapat dimanfaatkan untuk pembangunan. Jika wajib pajak (WP) telah membayar utang pajaknya tepat pada waktunya, maka dapat dikatakan WP tersebut taat.

Salah satu wujud transformasi pajak e-tax system yaitu e-filing. E-filing adalah media digital berbasis internet yang oleh wajib pajak dimanfaatkan melapor kewajiban pajaknya. (Amin, 2017). E-filing dapat dioperasikan dimana saja hanya dengan bermodalkan internet dan sistemnya dapat terakses 24 jam.

Tabel 1. Laporan Tahunan Direktorat Jenderal Pajak

\begin{tabular}{cccc}
\hline Tahun & Jumlah WP & $\begin{array}{c}\text { Rasio Kepatuhan } \\
\text { Penyampaian SPT (\%) }\end{array}$ & $\begin{array}{c}\text { Rasio WP Lapor } \\
\text { Via e-filling (\%) }\end{array}$ \\
\hline 2015 & $33,336,122$ & 60,42 & 2,51 \\
2016 & $36,446,616$ & 60,82 & 3,47 \\
2017 & $39,151,603$ & 72,64 & 4,44
\end{tabular}




\begin{tabular}{cccc}
\hline Tahun & Jumlah WP & $\begin{array}{c}\text { Rasio Kepatuhan } \\
\text { Penyampaian SPT (\%) }\end{array}$ & $\begin{array}{c}\text { Rasio WP Lapor } \\
\text { Via e-filling (\%) }\end{array}$ \\
\hline 2018 & $42,479,485$ & 71.10 & 8,83 \\
\hline
\end{tabular}

Sumber : https://www.pajak.go.id

Dari data Laporan Kinerja Direktorat Jenderal Pajak (LAKIN DJP) Tahun 2018 menyebutkan bahwa telah terjadi perubahan signifikan dalam proses administrasi perpajakan yang mana wajib pajak semakin mengarah pada proses perpajakan berbasis teknologi. Persentase penggunaan e-filing mencapai nilai 85\%. Meskipun banyak perubahan baik telah terjadi dengan adanya aplikasi e-filing, namun penerapan sistem tersebut tidaklah mudah. Fakta membuktikan bahwa meskipun aplikasi e-filing elektronik dapat mengurangi beban pajak dan kewajiban pembayaran pajak, namun belum semua wajib pajak melapor dengan aplikasi digital.

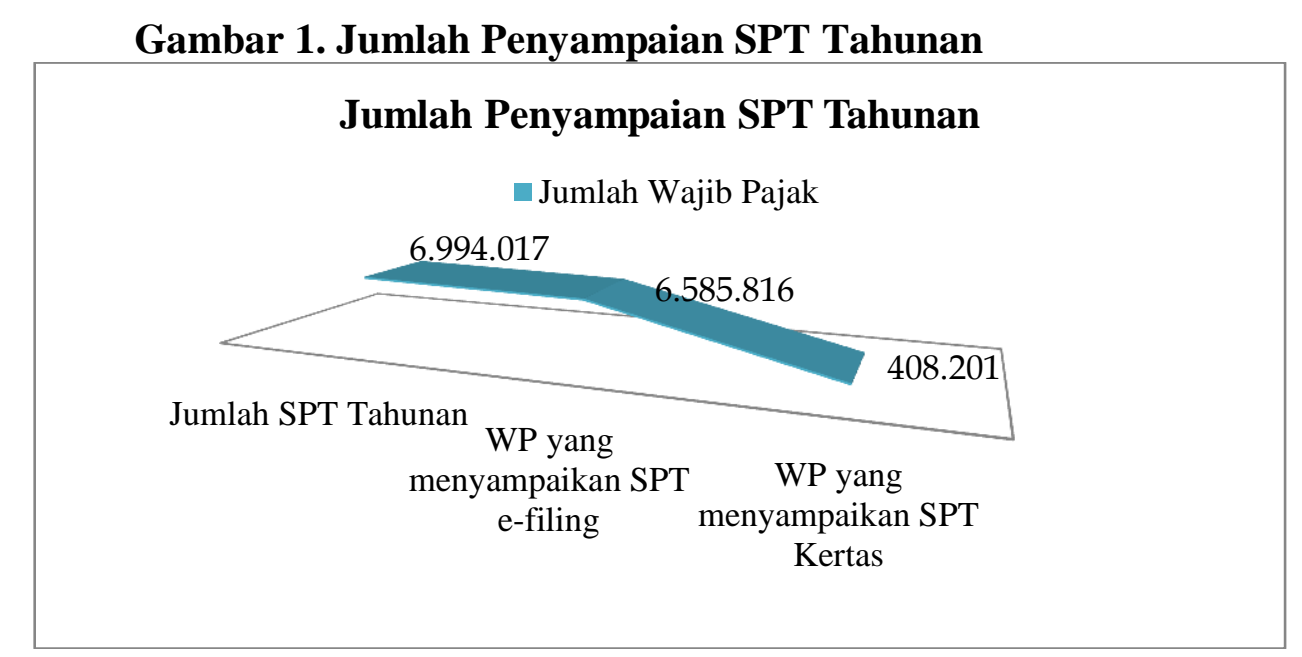

\section{Sumber : (KPP Makassar Barat, per 31 Maret 2019)}

Fakta jumlah penyampaian Surat Pemberitahuan (SPT) Tahunan periode pelaporan 31 Maret 2019, masih ada penyampaikan SPT Tahunan kertas yang masuk sebanyak 408.201 wajib pajak di KPP Makassar Barat. Hal ini bertentangan dengan (Menteri Keuangan Republik Indonesia Nomor 09/PMK03, 2018) yang mewajibkan penyampaian utang pajak dengan dokumen digital.

Kecakapan internet sebagai aspek pendukung ketaatan wajib pajak. Jika wajib pajak memiliki kecakapan tentang cara menggunakan internet maka akan mendukung pelaporan pembayaran pajak melalui media digital. Hasil penelitian (Aweloedin \& Maulana, 2018) menemukan bahwa pemahaman internet signifikan memengaruhi kepatuhan wajib pajak. Lebih lanjut, hasil penelitian (Suprayogo \& Hasymi, 2018) menemukan bahwa implementasi $e$-filing signifikan memengaruhi ketaatan wajib pajak melalui kecakapan internet.

Biaya ketaatan juga sebagai aspek yang mendukung wajib pajak taat. Sejumlah pengeluaran yang dibayar saat wajib pajak membayar pajaknya adalah biaya ketaatan dan dapat dibagi menjadi tiga yakni biaya uang, biaya waktu dan biaya anggapan. Bila banyak biaya muncul saat membayar utang pajak, akan memengaruhi wajib pajak tidak patuh (De Joman, Sastri, \& Patrini, 2020). Hasil penelitian (Hendri \& Hotang, 2019) 
menemukan bahwa biaya kepatuhan berpengaruh signifikan terhadap ketaatan wajib pajak.

Penelitian ini bertujuan : 1) untuk menganalisis $e$-filing berpengaruh pada ketaatan wajib pajak, 2) untuk menganalisis e-filing berpengaruh pada ketaatan wajib melalui moderasi kecakapan internet dan 3) untuk menganalisis e-filing berpengaruh pada ketaatan wajib pajak dengan tidak dimoderasi oleh biaya ketaatan.

\section{TINJAUAN PUSTAKA}

\section{Pengaruh $\boldsymbol{e}$-filing dengan ketaatan Wajib Pajak}

E-filing sebagai aplikasi digital dalam pelaporan pajak yang digunakan wajib pajak. Hasil Penelitian (Mendra, 2017), (Dewi \& Aryani, 2018) dan (Pradnyana \& Prena, 2019) menemukan bahwa patuhnya wajib pajak dipengaruhi implementasi $e$ filing. Hal ini mengindikasikan bahwa implementasi sistem $e$-filing merupakan variabel penting yang dapat mempengaruhi kemudahan dan kenyamanan wajib pajak dalam menunaikan kewajibannya sehingga akan menaikkan angka ketaatan wajib pajak.

Teori keperilakuan digunakan untuk menjelaskan bahwa terlihat perubahan sikap wajib pajak sebelum dan setelah adanya $e$-filing dalam melaporkan pajak. Aplikasi efiling yang dirasakan kemudahannya berimplikasi pada ketaatan dalam menunaikan utang pajak. (Amin, 2017). Untuk itu, penelitian ini mengajukan hipotesis sebagai berikut:

H1 : Ketaatan wajib pajak dipengaruhi oleh E-filing.

\section{Pengaruh e-filing dengan ketaatan Wajib Pajak Melalui Moderasi Pemahaman Internet}

Aplikasi e-filing yang menggunakan jaringan internet tentunya menuntut wajib pajak harus mengerti dan memahami cara mengoperasikan internet. Internet sebagai alat komunikasi digital yang menghubungkan sistem operasi dan perangkat yang berbeda di dunia. Aplikasi $e$-filing menjadikan pekerjaan wajib pajak menjadi ringan sebab dapat melapor pajak dimana saja hanya dengan bermodalkan jaringan internet sehingga angka ketaatan wajib pajak meningkat.

(Oktaviani, 2018), (Pratama, Yuesti, \& Sudiartana, 2019) dan (Manullang, Dewi, \& Yasa, 2020) menemukan bahwa pemahaman internet mampu memoderasi penerapan e-filing dengan kepatuhan wajib pajak. Dengan memahami internet akan memudahkan wajib pajak untuk melaporkan kewajiban pajaknya pada aplikasi $e$-filing.

Berbeda dengan (Lado \& Budiantara, 2018) menemukan bahwa pemahaman pemahaman internet bukan pemoderasi hubungan e-filing dengan ketaatan wajib pajak artinya melalui $e$-filing pelaporan pajak bisa dilakukan oleh wajib pajak meskipun wajib pajak tersebut kurang mengerti internet karena dapat dibantu orang terdekat untuk melaporkan pajaknya.

Teori keperilakuan menjelaskan bahwa kecakapan internet yang dimiliki wajib pajak akan memudahkannya pengaplikasikan e-filing dalam melaporkan kewajiban perpajakan secara digital. Untuk itu, diajukan hipotesis penelitian yaitu :

$\mathrm{H} 2$ : Kecakapan Internet sebagai pemoderasi penerapan sistem $e$-filing dengan ketaatan wajib pajak. 
Pengaruh Penerapan e-filing terhadap Ketaatan Wajib Pajak Melalui Moderasi Biaya Ketaatan

Terkait pelaporan pajak, wajib pajak mengeluarkan biaya kepatuhan atau Compliance Cost. Biaya ketaatan adalah jumlah uang yang dikeluarkan saat wajib pajak menunaikan utang pajaknya (Indriyani \& Askandar, 2018). Wajib pajak juga membayar biaya seperti biaya konsultasi, fotokopi, pengisian terkait SPT, biaya transport ke KPP, dll. (Fuadi \& Mangonting, 2103). Tingkat pemungutan biaya kepatuhan dapat mempengaruhi tingkat ketaatan wajib pajak. (Putri, Fionasari, \& Carolina, 2020).

Hasil penelitian (Pranata \& Supadmi, 2018) dan (Putri, Fionasari, \& Carolina, 2020) menemukan bahwa biaya ketaatan bukan pemoderasi e-filing dengan ketaatan wajib pajak. Namun, (Erwanda, Agustin, \& Mulyani, 2019) menemukan bahwa biaya ketaatan dapat memoderasi kepatuhan wajib pajak mengaplikasikan $e$-filing .

Teori keperilakuan menjelaskan bahwa biaya ketaatan yang dibayar wajib pajak sehubungan dengan pemenuhan utangnya tidak akan memengaruhi perilakunya untuk melaporkan SPT melalui aplikasi elektronik sesuai dengan jadwal pelaporan yang telah ditetapkan. Untuk itu, diajukan hipotesis penelitian yaitu :

H3 : Biaya ketaatan tidak mampu memoderasi pengaruh E-filing berpengaruh terhadap ketaatan wajib pajak.

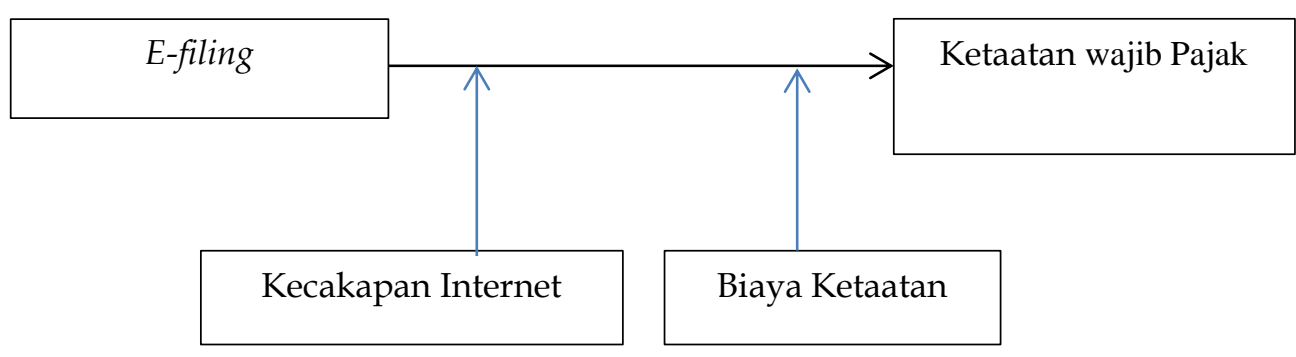

\section{Gambar 2. Kerangka Konseptual}

\section{METODOLOGI PENELITIAN}

\section{Pendekatan Penelitian}

Pendekatan saintific dalam penelitian ini berguna untuk menemukan pembenaran hipotesis yang diajukan melalui statistik sampai menemukan kesimpulan (Jogiyanto, 2014).

\section{Metode Pengumpulan Data}

Data didapatkan melalui kuesioner yang didistribusikan secara langsung kepada wajib pajak orang pribadi pada KPP Makassar Barat.

\section{Populasi dan Sampel}

Wajib Pajak E-Filling di KPP Pratama Makassar Barat sebanyak 30.127 orang pribadi adalah populasi dalam penelitian ini. Teknik accidental sampling yang telah dihitung dengan rumus Slovin digunakan untuk mengetahui total sampel yang berjumlah 100 orang wajib pajak orang pribadi.

\section{Teknik Analisis}

Model regresi berganda dengan pendekatan uji Moderated Regression Analysis (MRA) dengan program SPSS : 
$\mathrm{Y}=\alpha+\beta 1 \mathrm{X} 1+\beta 2 \mathrm{X} 1 \mathrm{Z} 1+\beta 3 \mathrm{X} 1 \mathrm{Z2}+\mathrm{e}$

Petunjuk :
$\alpha \quad$ : Konstansta.
$\beta \quad$ : Koefisien.
e : Error.
Y : Ketaatan Wajib Pajak
$\mathrm{X} 1 \quad$ : E-filing
X2 : Kecakapan Internet
X3 : Biaya Ketaatan
X1Z1 : Interaksi $e$-filing dengan kecakapan internet
$\mathrm{X} 1 \mathrm{Z2}$ : Interaksi $e$-filing dengan biaya ketaatan

\section{HASIL}

\section{Uji Normalitas}

Uji grafik normal probability plot, menunjukkan bahwa data dalam penelitian layak digunakan dan dikatakan normal, hal ini nampak pada gambar berikut :

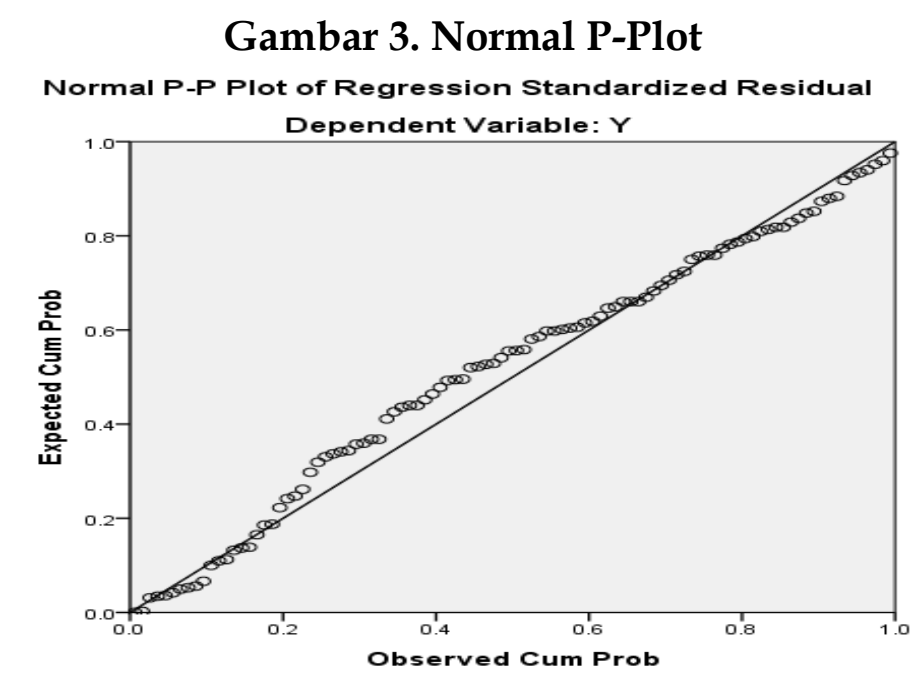

Gambar 3. Normal P-Plot

Sumber : data diolah (2020)

\section{Uji Multikolinearitas}

Tabel 2. Uji Multikolinearitas

\begin{tabular}{lcc}
\hline \multicolumn{1}{c}{ Variabel } & Tolerance & VIF \\
\hline e-filing & .533 & 1.876 \\
Kecakapan Internet & .650 & 1.539 \\
Biaya Ketaatan & .728 & 1.374 \\
\hline
\end{tabular}

Sumber : data diolah (2020)

Terlihat masing-masing variabel independen menunjukkan toleransi $>0,1$ dan VIF $<10$ sehingga multikolinearitas tidak memengaruhi model. 
Ikhtisar Analisis Regresi

Tabel 3. Ikhtisar Analisis Regresi

\begin{tabular}{|c|c|c|c|c|}
\hline Variabel & Koefisien & $t$-ratio & $\begin{array}{l}\text { Probability } \\
\text { Significancy }\end{array}$ & Keputusan \\
\hline $\mathrm{N}$ & 100 & & & \\
\hline Konstanta &, 225 & & & \\
\hline Adjusted $\mathrm{R}^{2}$ & 547 & & & \\
\hline$e$-filing & 0,548 & 5,300 & 0,000 & Signifikan \\
\hline $\begin{array}{l}\text { Interaksi } e \text {-filing } \\
\text { dengan kecakapan } \\
\text { internet }\end{array}$ & 0,297 & 3,651 & 0,000 & Signifikan \\
\hline $\begin{array}{l}\text { Interaksi } e \text {-filing } \\
\text { dengan biaya } \\
\text { ketaatan }\end{array}$ & 0,084 & ,919 & 0,350 & Tidak Signifikan \\
\hline
\end{tabular}

Sumber : data diolah (2020)

Ikhtisar analisis regresi menunjukkan varibael menunjukkan e-filing, kecakapan internet dan biaya ketaatan dengan nilai adjusted $\mathrm{R}^{2}$ sebesar 0,547 atau $54,70 \%$ memengaruhi ketaatan wajib pajak. Kemudian hasil analisis Moderated Regression Analysis (MRA) ditemukan persamaan :

$$
\mathrm{Y}=\alpha+0,548 \mathrm{X} 1+0,297 \mathrm{X} 1 \mathrm{Z} 1+0,84 \mathrm{X} 1 \mathrm{Z2}+\mathrm{e}
$$

\section{PEMBAHASAN}

\section{E-filing dengan terhadap Ketaatan Wajib Pajak}

Hipotesis 1 terbukti diterima yakni e-filing positif signifikan memengaruhi ketaatan wajib pajak. E-filing sangat membantu dalam pelaporan pajak, terlihat dari perubahan pelaporan SPT lebih cepat, lebih hemat dan lebih ramah lingkungan, lebih cepat menghitung, SPT mudah diisi, pengisian data SPT lebih lengkap, tidak merepotkan, dan tidak menyita waktu wajib pajak. Hal tersebut sangat bermanfaat bagi wajib pajak karena dimanapun wajib pajak berada, wajib pajak dapat melaporkan pajaknya.

Penelitian ini membuktikan teori keperilakuan terdukung dengan perubahan sikap wajib pajak membayar pajaknya terlihat lebih baik setelah adanya aplikasi $e$-filing. Efiling dirasakan mudah diaplikasikan oleh wajib pajak dalam melapor utangnya sehingga nilai ketaatan dapat meningkat. (Putri A. A., 2018). Penelitian ini juga mendukung temuan (Dewi \& Aryani, 2018), (Pradnyana \& Prena, 2019) dan (Nianty \& Hidayah, 2020) bahwa ketaatan wajib pajak signifikan dipengaruhi oleh $e$-filing.

\section{E-filing dengan Ketaatan Wajib Pajak Melalui Kecakapan Internet}

Hipotesis 2 terbukti diterima yakni kecakapan internet mampu memoderasi hubungan pengimplementasian $e$-filing dengan ketaatan wajib pajak. Artinya, e-filing menuntut wajib pajak harus cakap cara mengoperasikan internet. Dengan melapor pajak melalui $e$-filing dapat meringankan pekerjaan wajib pajak karena dapat melapor pajak dimana saja hanya dengan bermodalkan jaringan internet sehingga diharapkan dapat meningkatkan ketaatan wajib pajak. 
Penelitian ini membuktikan teori keperilakuan terdukung bahwa wajib pajak yang mengetahui cara mengaplikasikan internet akan mampu mengaplikasikan e-filing untuk menyelesaikan kewajiban pajaknya secara digital yang akan dirasakan lebih efisien dan efektif. (Suprayogo \& Hasymi, 2018) menyatakan kecakapan internet yang dikuasasi oleh wajib pajak akan mendorong peningkatan ketaatannya membayar pajak.

Penelitian ini terbukti mendukung temuan (Oktaviani, 2018), (Pratama, Yuesti, \& Sudiartana, 2019) dan (Manullang, Dewi, \& Yasa, 2020) yakni pemahaman internet mampu memoderasi $e$-filing dengan kepatuhan wajib pajak. Namun, temuan penelitian ini berbeda dengan (Lado \& Budiantara, 2018) bahwa kecakapan internet bukan pemoderasi Sistem E-filing dengan Kepatuhan Wajib Pajak artinya artinya melalui $e$ filing pelaporan pajak bisa dilakukan oleh wajib pajak meskipun wajib pajak tersebut kurang mengerti internet karena dapat dibantu orang terdekat untuk melaporkan pajaknya.

\section{E-filing dengan Ketaatan Wajib Pajak Tidak Melalui Moderasi Biaya Ketaatan.}

Hipotesis 3 terbukti diterima yakni biaya ketaatan tidak mampu memoderasi $e$ filing dengan ketaatan wajib pajak. Artinya, dalam mengoperasian e-filing, wajib pajak masih menanggung biaya internet dan biaya mencetak dokumen pelaporan pajaknya. Hasil ini mendukung pernyataan (Fuadi \& Mangonting, 2103) yakni sejumlah biaya dikeluarkan wajib pajak selain membayar pajaknya seperti biaya konsultasi, transport, fotocopy dan lain-lain.

Penelitian ini mendukung teori keperilakuan yakni biaya ketaatan yang dikeluarkan oleh wajib pajak saat melaporkan utang pajaknya tidak akan memengaruhi perilaku wajib pajak melaporkan SPT melalui aplikasi $e$-filing sesuai jadwal pelaporan yang telah ditetapkan. Wajib pajak tetap menggunakan aplikasi e-filing karena manfaat yang dirasakannya walaupun masih ada biaya yang dikeluarkan (Putri, Fionasari, \& Carolina, 2020).

Temuan (Tresno \& Rizky, 2013), (Pranata \& Supadmi, 2018) dan (Putri, Fionasari, \& Carolina, 2020) terdukung oleh penelitian ini bahwa biaya ketaatan tidak mampu memoderasi $e$-filing terhadap ketaatan wajib pajak. Namun, hasil penelitian ini berbeda dengan (Erwanda, Agustin, \& Mulyani, 2019) yang menemukan bahwa penerapan $e$-filing dengan ketaatan wajib pajak diperkuat oleh biaya ketaatan.

\section{SIMPULAN}

Simpulan yang dapat diambil berdasarkan setelah menguji hipotesis adalah : $e$ filing positif dan signifikan memengaruhi ketaatan wajib pajak, kecakapan internet sebagai pemoderasi e-filing dengan ketaatan wajib pajak sedangkan biaya ketaatan bukan pemoderasi hubungan $e$-filing dengan ketaatan wajib pajak.

\section{SARAN}

Penelitian ini menyarankan kepada Pemerintah agar membuat kebijakan yang memberikan kemudahan bagi pajak agar wajib pajak tidak mengeluarkan biaya ketaatan yang besar yang membuat wajib pajak tidak patuh menerapkan $e$-filing untuk melapor pajaknya.

\section{DAFTAR PUSTAKA}


Amin, A. (2017). Faktor-faktor Yang Mempengaruhi Intensitas Perilaku Wajib Pajak dalam Penggunaan E-Filing pada Kantor Pelayanan Pajak Madya Makassar. Akmen Jurnal Ilmiah, 14(2), 211-220.

Aweloedin, D. T., \& Maulana, M. A. (2018). Pengaruh Penerapan Sistem e-filing, Pemahaman Internet dan Kesadaran Wajib Pajak Terhadap kepatuhan Wajib pajak Pratama Depok Cimanggis. Jurnal Rekayasa Informasi, 7(1).

De Joman, J. C., Sastri, I. M., \& Patrini, L. (2020). Pengaruh Biaya Kepatuhan, Pemeriksaan Pajak dan Penerapan E-SPT Terhadap Kepatuhan Wajib Pajak. Jurnal Riset Akuntansi Warnadewa, 1(1).

Dewi, S. K., \& Aryani, N. L. (2018). Pengaruh Kesadaran Wajib Pajak, Sanksi Perpajakan, E-Filing dan Tax Amnesty Terhadap Pelaporan Wajib Pajak. Jurnal Akuntansi Universitas Udayana, 22(1).

Erwanda, M., Agustin, H., \& Mulyani, E. (2019). Pengaruh Penerapan e-filing dan Pengetahuna Perpajakan terhadap Kepatuhan Wajib Pajak dengan Biaya kepatuhan Sebagai Variabel Moderasi. JEA.Jurnal Eksplorasi Akuntansi, 1(3), 1510-1517.

Fuadi, A. O., \& Mangonting, Y. (2103). Pengaruh Kualitas Pelayanan Petugas Pajak, Sanksi Perpajakan dan Biaya Kepatuhan Pajak Terhadap Kepatuhan Wajib Pajak UMKM. Tax \& Accounting Review, 1(1), 35-42.

Hendri, \& Hotang, K. B. (2019). E-Filing, Pemahaman, Sanksi Perpajakan, Biaya kepatuhan dan Kepuasan Kualitas Pelayanan Terhadap Kepatuhan Pelaporan SPT Tahunan Wajib Pajak Orang Peribadi. JAAF (Jornal of Applied Accounting and Finance, 3(2).

Indriyani, N., \& Askandar, N. S. (2018, Agustus). Pengaruh Kualitas Pelayanan, Sanksi Perpajakan, Biaya-biaya Kepatuhan Pajak dan Penerapan E-filing Pada Kepatuhan Wajib Pajak. E-JRA Fakultas Ekonomi dan Bisnis Universitas Islam Malang, 07(07).

Jogiyanto, H. (2014). Metodologi Penelitian Bisnis (salah kaprah dan pengalamanpengalaman). Yogyakarta: BPFE.

Lado, Y. O., \& Budiantara, M. (2018). Pengaruh Penerapan Sistem E-Filing Terhadap Kepatuhan Wajib Pajak Orang Pribadi Pegawai Negeri Sipil dengan Pemahaman Internet Sebagai Variabel Pemoderasi. Jurnal Riset Akuntansi Mercu Buana (JRAMB), 4(1).

Manullang, G. D., Dewi, P. M., \& Yasa, I. P. (2020). Pengaruh Penerapan Sistem EFiling dan E-Billing Terhadap Kepatuhan Wajib Pajak Dengan Pemahaman 
Internet Sebagai Varoabel Moderasi. JIMAT Universitas Pendidikan Ganesha, $11(1)$.

Mendra, N. Y. (2017, September). Penerapan Sistem e-filing terhadap kepatuhan wajib pajak dengan pemahaman internet. JUARA Jurnal Akuntansi, 7(2).

Menteri Keuangan Republik Indonesia Nomor 09/PMK03. (2018). Tentang Surat Pemberitahuan (SPT). Jakarta.

Nianty, D. A., \& Hidayah, N. (2020). Determinan E-Tax Service Terhadap Peningkatan Tax Compliance Pada Kpp Pratama Makassar Utara. Jurnal Equilibrium, 9(2).

Oktaviani, R. M. (2018). Pemahaman Internet Sebagai Pemoderasi Penerapan Sisitem E-Filing Terhadap Kepatuhan Wajib Pajak. Prosiding Seminar Nasional Multi Disiplin Ilmu dan Call For Papers. 4. Semarang: UNISBANK.

Pradnyana, I. P., \& Prena, G. D. (2019). Pengaruh Penerapan Sistem E-Filing, E-Billing dan Pemahaman Perjakakan Terhadap Kepatuhan Wajib Pajak Orang Pribadi KPP Pratama Denpasar Timur. Wacana Ekonomi, 18(1).

Pranata, K. K., \& Supadmi, N. (2018, Juli). Pengaruh Penerapan e-filing pada Kepatuhan Wajib pajak Badan dengan biaya Kepatuhan Pajak sebagai Variabel Moderasi. E-Jurnal Akuntansi Universitas Udayana, 24(1), 633-661.

Pratama, I. M., Yuesti, A., \& Sudiartana, I. (2019, April). Pengaruh Penerapan Sistem eFiling dan E-Billing Terhadap Kepatuhan Wajib Pajak dengan Pemahaman Internet Sebagai Variabel Moderasi pada KPP Pratama Gianyar. Jurnal Sains, Akuntansi dan Manajemen (JSAM), 1(4).

Putri, A. A. (2018, Desember). Kepatuhan Wajib Pajak : Studi Aspek Penerapan EFiling, Pemahaman Perpajakan, Kesadaran dan Sosialisasi Pajak. Jurnal Akuntansi dan Ekonomika, 8(2).

Putri, A. A., Fionasari, D., \& Carolina, E. (2020). Biaya Kepatuhan Memoderasi Penerapan E-Filing Terhadap kepatuhan Wajib Pajak Badan. Tax Center $e$ Journal UIN Suska, 1(1), 1-21.

Suprayogo, S., \& Hasymi, M. (2018, Agustus). Pengaruh Penerapan Sistem E-Filing Terhadap Kepatuhan Wajib Pajak Orang Pribadi Dengan Pemahaman Internet Sebagai Variabel Moderasi Pada Kantor Pelayanan Pajak Pratama Jakarta Jatinegara. Profita : Komunikasi Ilmiah Akuntansi dan Perpajakan, 11(2).

Tresno, I. P., \& Rizky, S. A. (2013). Pengaruh Persepsi penerapan sistem e-filing terhadap tingkat kepatuhan Wajib Pajak Badan dengan perilaku wajib pajak sebagai variabel intervening. Prosiding Simposium Perpajakan 4. Jakarta: Fakultas Ekonomi Universitas Negeri Jakarta. 